\title{
Relapse to Cocaine- and Heroin-Seeking Behavior Mediated by Dopamine D2 Receptors Is Time-Dependent and Associated with Behavioral Sensitization
}

\author{
Taco J. De Vries, Ph.D., Anton N. M. Schoffelmeer, Ph.D., Rob Binnekade, Halfdan Raasø,
} and Louk J. M. J. Vanderschuren, Ph.D.

The sensitizing properties of drugs of abuse have been proposed to play an important role in the persistence of drug seeking behavior. We decided to evaluate the temporal relationship of dopamine $\mathrm{D} 2$ receptor-mediated drug seeking behavior and behavioral sensitization in animals with a history of cocaine and heroin self-administration. During early phases of withdrawal ( $<1$ week), activation of dopamine D2 receptors with quinpirole resulted in robust, dose-dependent, reinstatement of (non-reinforced) responding in both cocaine- and heroin-trained rats. Cocaine and heroin seeking induced by quinpirole was associated with a dramatic enhancement of the psychomotor stimulant effects of the D2 agonist, indicating that sensitization to D2-mediated events had developed. During the late phase of withdrawal ( $>3$ weeks), reinstatement of cocaine seeking by quinpirole was still apparent, but less robust. In heroin-trained rats, increases of responding were no longer observed. Interestingly, behavioral sensitization to quinpirole was still observed in cocaine-trained rats, but was absent in heroin-trained rats. Thus, it appears that dopamine $D 2$ receptors have a time-dependent role in relapse to cocaine and heroin seeking which is strongly associated with a behaviorally sensitized state.

[Neuropsychopharmacology 26:18-26, 2002]

(C) 2001 American College of Neuropsychopharmacology.

Published by Elsevier Science Inc.
KEY WORDS: Drug-seeking; Relapse; Behavioral sensitization; Temporal changes; Dopamine D2 receptors; Drug self-administration; Cocaine; Heroin

Studying the neurobiology of drug addiction in laboratory animals, recent advances indicate that drug seeking

From the Research Institute Neurosciences Vrije Universiteit, Drug Abuse Program, Department of Medical Pharmacology, VU Medical Center, Amsterdam, The Netherlands.

Address correspondence to: Taco J. De Vries, Research Institute Neurosciences Vrije Universiteit, Department of Medical Pharmacology, Van der Boechorststraat 7, 1081 BT Amsterdam, The Netherlands, Tel.: (31) 20 4448101, Fax: (31) 20 4448100, E-mail: tj.de_vries. pharm@med.vu.nl

Received January 2, 2001; revised March 26, 2001; accepted May 24, 2001.

Online publication: 5/25/01 at www.acnp.org/citations/Npp 052501124 behavior can be triggered by drug-associated (conditioned) cues, by stressful stimuli and by reexposure to the previously experienced drug (McFarland and Ettenberg 1997; Self et al. 1996; De Vries et al. 1998b; Shaham et al. 2000); events also known to trigger drug craving and relapse in human addicts (Meyer and Mirin 1979; Kosten et al. 1986; O'Doherty and Davies 1987; Jaffe et al. 1989; McFall et al. 1992; Ludwig et al. 1994; De Wit 1996). Moreover, in laboratory animals drug-seeking behavior can be evoked and observed even after prolonged periods of drug abstinence (weeks to at least one month) (Shaham et al. 1994; De Vries et al. 1998b; Katner et al. 1999). Therefore, stimulus-induced reinstatement of extinguished self-administration behavior is widely accepted as an animal model representing defining characteristics of relapse behavior in humans. 
The identification of the neurobiological factors that maintain drug seeking may provide tools that interfere in the complex process of relapse behavior in human addicts. In this respect, it is generally believed that long-lasting neuroadaptive changes in the mesolimbic dopamine circuitry are crucial for ongoing addiction behavior (Robinson and Berridge 1993; Self and Nestler 1998). Indeed, there is ample evidence for a central role of the dopaminergic ventral tegmental area (VTA) and its main projection target, the nucleus accumbens, in the motivational effects of addictive drugs (for reviews: Wise and Bozarth 1987; Koob 1992; Robinson and Berridge 1993). In general, repeated exposure to drugs of abuse induce time-dependent neuroadaptations within the mesolimbic dopamine circuitry, thought to underlie an enhanced behavioral responsiveness (sensitization) upon renewed exposure to the drug. Although it has been proposed that the sensitizing effects of drugs of abuse may enhance their incentivemotivational properties and, as such, play an important role in the persistence of drug seeking behavior (Robinson and Berridge 1993), compelling evidence in favor of this incentive-sensitization view of addiction is still scarce (De Vries et al. 1998b; Deroche et al. 1999).

Enhanced responsiveness of the mesolimbic dopamine system is often observed as a facilitated stimulus-induced release of nucleus accumbens dopamine, as measured both in vitro and in vivo. However, enhanced release of accumbens dopamine is variable or absent during early drug withdrawal periods, i.e. within the first week (for recent review: Vanderschuren and Kalivas 2000). These observations have questioned the involvement of mesolimbic dopamine in the early expression of drug seeking. Also, it raises the possibility that the effectiveness of a neuronal substrate to mediate relapse-like behavior may depend on the phase of drug withdrawal. In this respect, it is interesting to note that dopamine D2-like receptor activation seems to cause heroin seeking in rats during early (Wise et al. 1990), but not late phase of withdrawal (De Vries et al. 1999). Therefore, in order to unravel the precise mechanisms that control drug seeking, it is important to study the temporal profile of the possible factors involved.

The present study was designed to evaluate the role of D2-like receptor activation in drug-seeking behavior in detail, i.e.: i) by comparing reinstatement of heroinand cocaine-seeking at early $(<1$ week) and late $(>3$ weeks) withdrawal stages and ii) by evaluating the contribution of drug hyperresponsiveness, i.e. to determine whether reinstatement of heroin and cocaine seeking is associated with temporal changes in the psychomotor stimulant effects of the D2-like agonist quinpirole.

\section{METHODS}

\section{Animals}

Male Wistar rats (Harlan, The Netherlands) weighing 270-320g at the start of the experiment were housed in- dividually in a temperature-controlled room on a reversed 12-hr light-dark cycle (lights off 8:00 A.M.) with food and water available ad libitum. Animals were allowed to adapt to the reversed light-dark cycle for at least 10 days. All experiments were approved by the Animal Care Committee of the Vrije University of Amsterdam.

\section{Surgical Procedure}

Intravenous silicon catheters (Sylastic; 0.025" OD, 0.012" ID) were surgically implanted in the right jugular vein under ketamine $(60 \mathrm{mg} / \mathrm{kg}$, IM) / xylazine ( $4 \mathrm{mg} / \mathrm{kg}$, IP) anesthesia. The catheter was secured to the vein with two silk sutures and passed subcutaneously to the top of the skull. The distal end of the catheter was attached to a connector pedestal (Plastics One, Düsseldorf, Germany) anchored to the skull with four surgical screws and dental cement. Catheter patency was maintained by daily infusion of $0.15 \mathrm{ml}$ of a sterile saline solution containing heparin (20 units $/ \mathrm{ml})$.

\section{Experiment 1: Reinstatement Studies}

Apparatus. Custom made operant chambers housed in ventilated enclosures were used. The chambers were fitted with a dim red house light and two small nosepoke holes ( $2.5 \mathrm{~cm} \mathrm{ID)} \mathrm{separated} 15 \mathrm{~cm}$ from each other. An infusion pump (World Precision Instruments, Mauer, Germany), which was connected via polyethylene tubing (PE50) to the catheter, was used for solution delivery. The animal was allowed free movement within the chamber by means of a liquid swivel (Plastics One) which was connected to the headmount via a tether. One hole was designated as "drug active"; nose poking in this hole resulted in the delivery of $50 \mu \mathrm{l}(40-60 \mu \mathrm{l}$ depending on the size of the rat) of a drug solution over a period of $2 \mathrm{~s}$. Pokes in the inactive hole were monitored, but were without consequences. A 15-s time-out period immediately followed each infusion during which the red house light was off and further nose poking was without consequences. A computer interfaced to the chambers was used for equipment operation and data collection.

Training and Extinction Phase. Self-administration sessions commenced 5-7 days following surgery and were performed between 10:00 A.M. and 6:00 P.M.. Animals were allowed to self-administer heroin $(50 \mu \mathrm{g} / \mathrm{kg} /$ inj.) during 14 daily 3-hr sessions or cocaine (500 $\mu \mathrm{g} /$ $\mathrm{kg} /$ inj.) during 10 daily 2 -hr sessions on a continuous schedule of reinforcement (FR1). The number of cocaine injections was limited to 60 per session. In some experiments, control animals which received saline instead of drug infusions were run simultaneously. Self-administration sessions were followed by extinction sessions during which drug solutions were replaced by saline. All other experimental conditions were kept identical. Extinction sessions (two hours) were conducted either 
twice daily for two days (short-term withdrawal) or once daily for 18 days (long-term withdrawal).

Reinstatement Phase. To reduce the influence of drugassociated cues during drug-induced reinstatement testing, house lights, infusion pumps and the sound of the electrical switch that accompanied nose poke responses in the past were turned off. Baseline levels of responding ( $<10$ nose pokes in $2 \mathrm{hr}$ ) under these conditions were reached after two 2-hr sessions (pre-reinstatement phase). In the short-term withdrawal group, two pre-reinstatement sessions were performed on day 3 of withdrawal. Tests for reinstatement of heroin- and cocaine-seeking behavior following priming injections of the dopamine D2/D3 agonist quinpirole (0.05-1.0 $\mathrm{mg} / \mathrm{kg}, \mathrm{SC}$ ) were then conducted in a random design. On the first day, i.e. withdrawal day 4 or 21 , a saline injection was given and (non-reinforced) nose poking was measured for a period of four hours and served as a baseline response. Previous experiments showed that following a drug priming session, responding upon a saline injection the following day was not different from that during the first saline session. Therefore, the effects of the different doses of quinpirole were evaluated in four consecutive daily sessions. Animals were placed in the operant chambers $30 \mathrm{~min}$ after drug injection, except for the $0.05 \mathrm{mg} / \mathrm{kg}$ dose of quinpirole, following which animals were placed in the chambers immediately. Responses in both the previously drug-paired (active) hole and the inactive hole were recorded for four hours.

\section{Experiment 2: Locomotor Sensitization}

In separate groups of rats, the locomotor response to quinpirole $(0.5 \mathrm{mg} / \mathrm{kg}, \mathrm{SC})$ was determined either $3-4$ days or 21-22 days after discontinuation of saline, heroin and cocaine self-administration. Animals were subjected to the same extinction protocol as in the procedure described above.

Apparatus. Locomotor activity was monitored by a video-tracking system (EthoVision, Noldus Information Technology BV, Wageningen, The Netherlands) which read the position of the animal 5 times/sec. The system simultaneously records the movements of eight rats placed in separate black Perspex cages $(40 \times 40 \times$ $35 \mathrm{~cm}$ ). White noise was used to reduce the influence of surrounding sounds. Experiments were performed during the dark phase of the light-dark cycle under dim red light conditions between 10:00 A.M. and 3:00 P.M.

Procedure. Following the 3, 4, 21 and 22 day withdrawal period, rats (4 saline- and 4 drug-trained rats) were habituated to the locomotor cages for two hours. Subsequently, rats received a saline injection (SC) and their activity was recorded for one hour. Then, all rats received quinpirole $(0.5 \mathrm{mg} / \mathrm{kg}, \mathrm{SC})$ and their activity was recorded for two hours. Locomotor activity was expressed as distance traveled $(\mathrm{cm})$ per 10-min interval.

\section{Statistical Analysis}

Reinstatement data (expressed as number of nose pokes in previous active and inactive holes during a 2-hr time block) were subjected to normality tests and subsequently analyzed by GLM ANOVA; locomotor data (expressed as horizontal distance moved $(\mathrm{cm})$ per 10-min interval) were analyzed by 2 -factor (pretreatment $X$ time-interval) repeated measures ANOVA. ANOVAs were followed by the Newman-Keuls Multiple-Comparison test using the NCSS 2000 software package.

\section{RESULTS}

Acquisition data of i.v. cocaine and heroin self-administration were similar to those described previously (De Vries et al. 1998a,b). Acquisition of cocaine self-administration was usually established within the first session and average number of cocaine infusions during the last four sessions amounted to $51 \pm 8$. Heroin infusions gradually increased over time and a clear difference between heroin and saline self-administration was found from session 4 on. Average number of heroin infusions during the last four sessions was $27 \pm 3$ (data not shown).

\section{Experiment 1: Reinstatement Studies}

Animals that reached the criterion for extinction, i.e. $<10$ nose pokes during a 2-hr session, were used for the reinstatement studies. In the short-term withdrawal group about $90 \%$ of the animals could be included and in the longterm withdrawal group all animals reached the criterion.

Reinstatement of Cocaine Responding by Quinpirole. Figure 1, left panel, shows the results of priming injections of quinpirole $(0.05-1.0 \mathrm{mg} / \mathrm{kg}$, SC) in four consecutive daily 4-hr sessions on non-reinforced nose poking behavior starting on day 4 of withdrawal from cocaine self-administration (short-term withdrawal group). A significant overall effect of quinpirole on nose poking behavior in the previous cocaine-paired hole was found during the first 2-hr time block $(\mathrm{F}(4,44)=18.77, p<$ $.0001)$ and the second $(\mathrm{F}(4,44)=15.06, p<.0001)$. Twofactor interactions analysis (Newman-Keuls) indicated that the $0.2 \mathrm{mg} / \mathrm{kg}$ dose enhanced responding only during the first 2 -hr interval $\left({ }^{* * *} p<.001\right)$, whereas the 0.5 $\mathrm{mg} / \mathrm{kg}$ dose increased responding during both 2-hr intervals $\left({ }^{* * *} p<.001\right)$. Priming with $1.0 \mathrm{mg} / \mathrm{kg}$ quinpirole resulted in a delay of responding, which reached significance during the second 2-hr block $\left({ }^{* *} p<.01\right)$, illustrating dose-dependency that is typical for reinstatement. Priming with quinpirole did not significantly increase responding in the inactive hole, indicating that the behavior of the animal was directed specifically to the nose poke hole previously associated with cocaine.

In the long-term withdrawal group (Figure 1, right panel), quinpirole injections resulted in reinstatement of 


\section{short-term withdrawal}

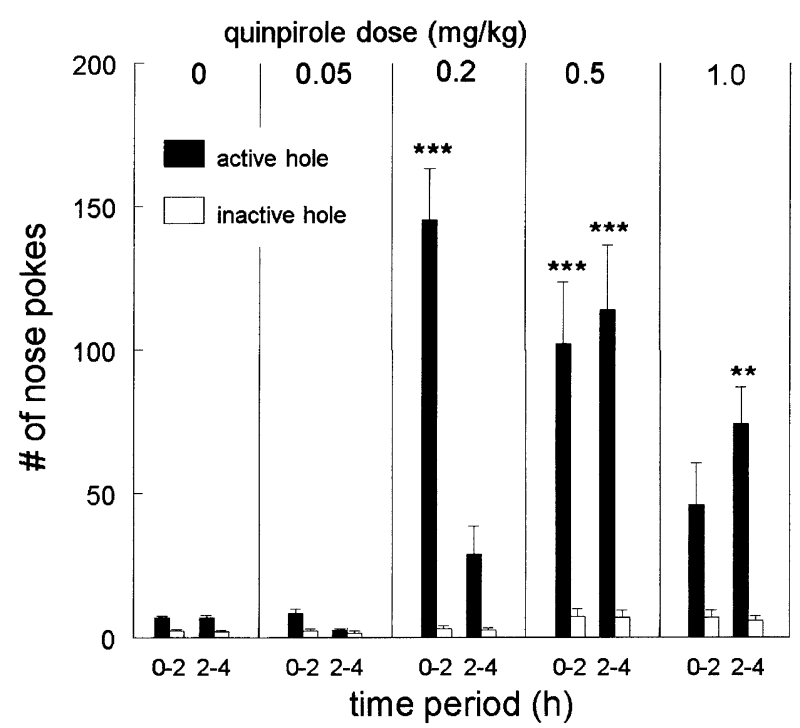

long-term withdrawal

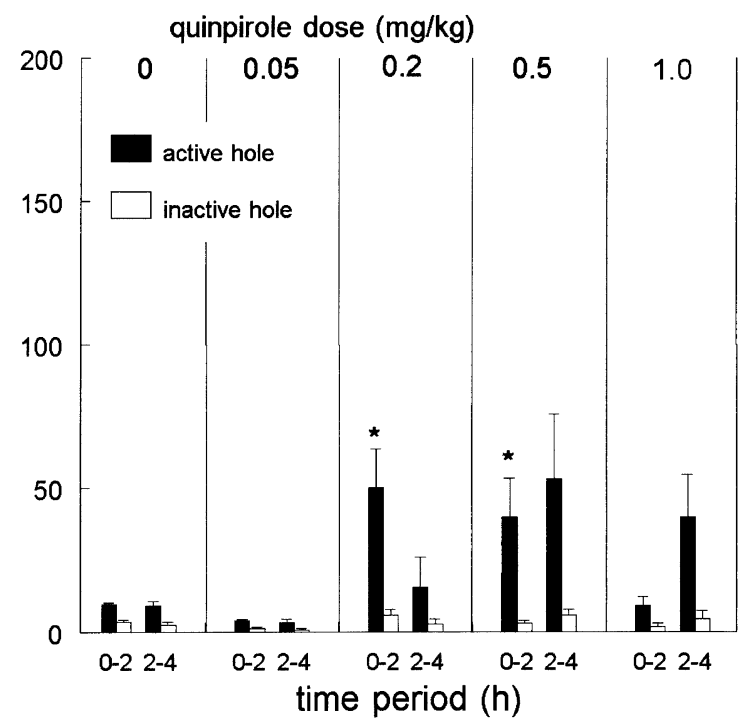

Figure 1. Reinstatement of cocaine seeking. The effect of quinpirole $(0-1.0 \mathrm{mg} / \mathrm{kg}, \mathrm{SC}, \mathrm{n}=10)$ on responding in the nose poke hole previously associated with cocaine infusion (active hole) and in the inactive hole, in animals withdrawn from cocaine self-administration for four days (short-term withdrawal) and 21 days (long-term withdrawal). Responding (mean \pm S.E.M. nose pokes) was measured during two 2 -hr time blocks to illustrate dose-dependency of the effect. ${ }^{*} p<.05$ for significant differences to the saline injection.

cocaine seeking, although to a lesser extent as compared to the short-term withdrawal group. Significant increases of responding in the previously cocaine-paired hole were found during the first 2-hr time block $(\mathrm{F}(4,38)=4.40, p=$ $.0057)$ at doses of 0.2 and $0.5 \mathrm{mg} / \mathrm{kg}\left({ }^{*} p<.05\right)$. Increased responding observed during the second interval just failed to reach significance $(\mathrm{F}(4,38)=2.35, p=.074)$. Again, no significant increases in the inactive (not previously associated with cocaine) hole were observed.

Reinstatement of Heroin Responding by Quinpirole. Figure 2, left panel, shows the results of priming injections of quinpirole $(0.05-1.0 \mathrm{mg} / \mathrm{kg}$, SC) during four consecutive daily 4-hr sessions on non-reinforced nose poking behavior following short-term withdrawal (4 days) of heroin self-administration. A significant overall effect of quinpirole on nose poking behavior in the previous heroin-paired hole was found during the first 2-hr time block $(\mathrm{F}(4,34)=2.42, p=.048)$ and during the second $(\mathrm{F}(4,34)=4.22, p=.008)$. The $0.2 \mathrm{mg} / \mathrm{kg}$ dose reinstated heroin seeking during the first 2-hr interval $\left({ }^{*} p<.05\right)$ and the $0.5 \mathrm{mg} / \mathrm{kg}$ dose during the second 2 -hr interval $\left({ }^{*} p<.05\right)$. No significant increases in responding in the inactive hole were observed.

In the long-term withdrawal group (Figure 2, right panel), quinpirole did no longer enhance responding in the previous heroin-paired hole during the first $(\mathrm{F}(4,34)=$ $0.42, \mathrm{NS})$ and second $(\mathrm{F}(4,34)=2.61, \mathrm{NS})$ 2-hr time block.

\section{Experiment 2: Locomotor Studies}

Changes in sensitivity to the locomotor stimulating effects of quinpirole in cocaine- and heroin-trained rats were determined using the $0.5 \mathrm{mg} / \mathrm{kg}$ dose, which showed the most robust effects in the reinstatement paradigm.

Figure 3 shows the effect of quinpirole on locomotor activity in animals withdrawn from cocaine and saline self-administration. In the short-term withdrawal groups (Figure 3, panel A), cocaine-trained rats were found extremely sensitive to the stimulant effects of the D2-like agonist as compared to saline-trained rats $(\mathrm{F}(1,168)=$ $13.69, p=.0030)$. Following long-term withdrawal of cocaine self-administration (Figure 3, panel B), the stimulant effect of quinpirole was still enhanced compared to that in saline-trained rats $(\mathrm{F}(1,180)=6.98, p=.02)$.

Figure 4 shows the effect of quinpirole on locomotor activity in animals withdrawn from heroin and saline self-administration. Similar to cocaine-trained, herointrained rats were hypersensitive to the stimulant effects of quinpirole following short-term withdrawal (Figure 4 , panel $\mathrm{A} ;(\mathrm{F}(1,192)=9.73, p=.0089)$. In the long-term withdrawal group (Figure 4, panel B), heroin-trained animals did no longer show an enhanced locomotor response to quinpirole $(\mathrm{F}(1,187)=0.85, \mathrm{NS})$.

Both cocaine- and heroin-trained rats, as compared to saline-trained rats, did not show any changes in their response to a saline injection in any condition. 
short-term withdrawal

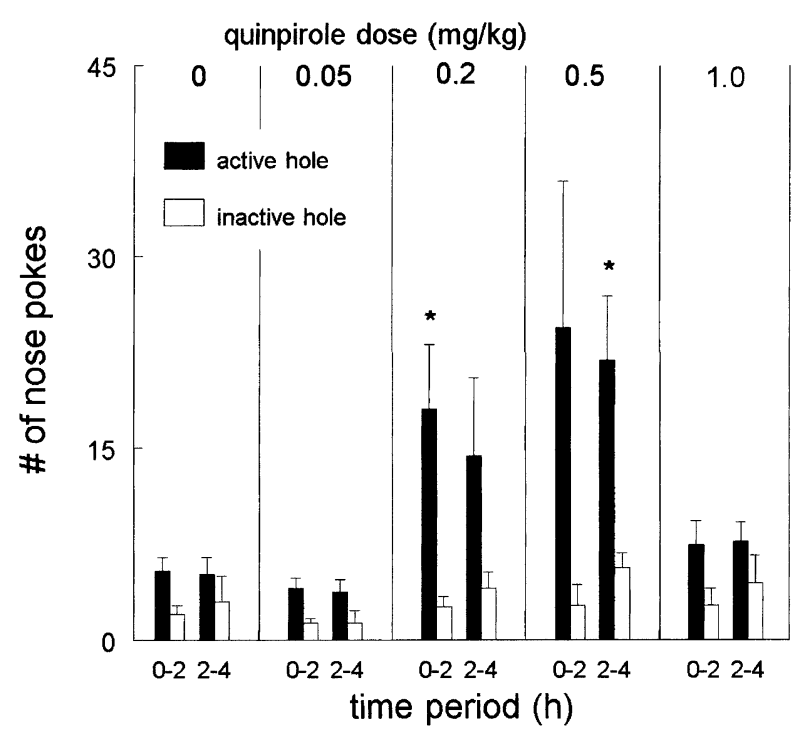

long-term withdrawal

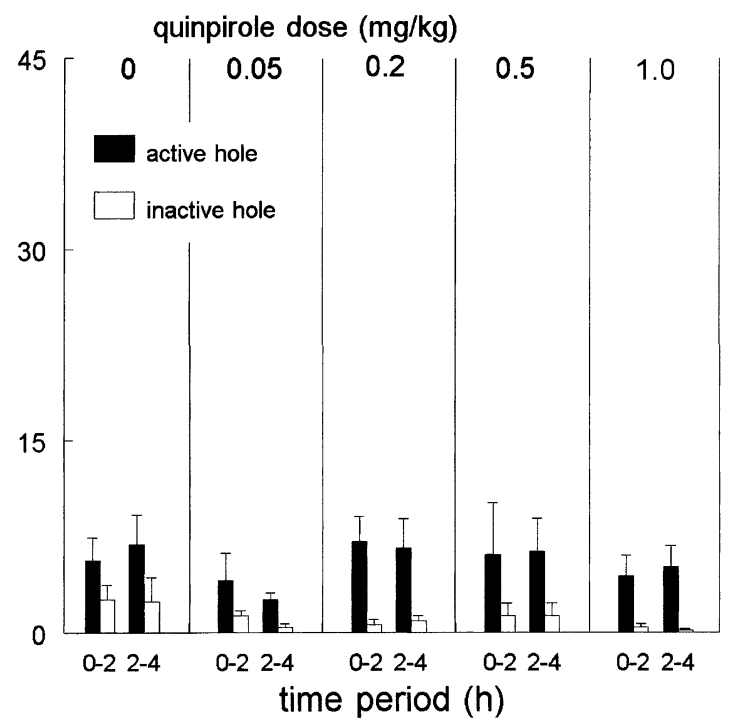

Figure 2. Reinstatement of heroin seeking. The effect of quinpirole $(0-1.0 \mathrm{mg} / \mathrm{kg}, \mathrm{SC}, \mathrm{n}=8)$ on responding in the nose poke hole previously associated with heroin infusion (active hole) and in the inactive hole, in animals withdrawn from heroin self-administration for 4 days (short-term withdrawal) and 21 days (long-term withdrawal). Responding (mean \pm S.E.M. nose pokes) was measured during two 2-hr time blocks to illustrate dose-dependency of the effect. ${ }^{*} p<.05$ for significant differences to the saline injection.

\section{DISCUSSION}

Using an animal model of relapse to drug seeking, we observed that during early withdrawal from i.v. cocaine and heroin self-administration, activation of D2-like dopamine receptors with quinpirole resulted in robust re- instatement of cocaine and heroin seeking. Parallel analysis of locomotor activity revealed that at this early stage of withdrawal the psychomotor stimulant effects of quinpirole were strongly enhanced in both heroinand cocaine-trained rats, compared to saline-trained animals. Drug seeking evoked by quinpirole clearly de-
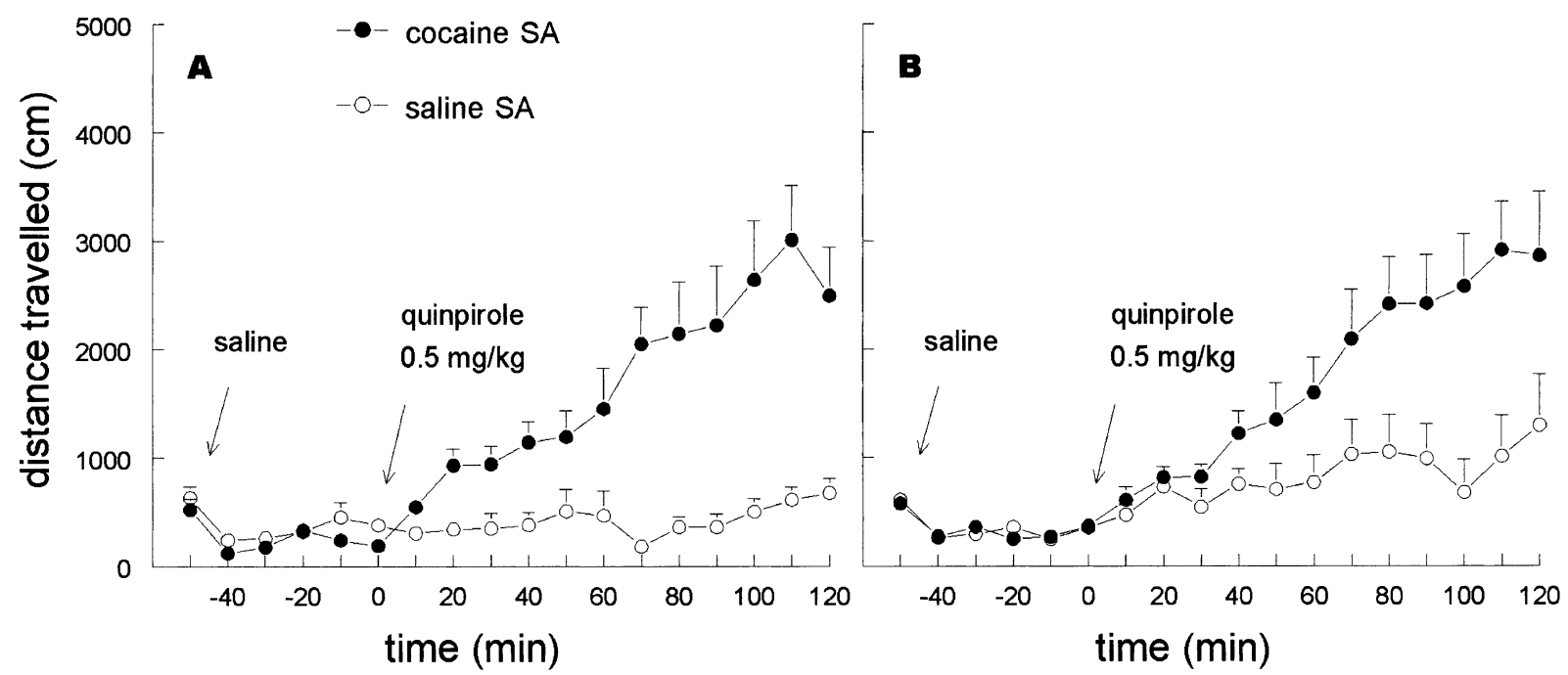

Figure 3. Locomotor effects of quinpirole following cocaine self-administration. Locomotor activity analysis after saline and quinpirole $(0.5 \mathrm{mg} / \mathrm{kg}$, SC) injection in animals withdrawn from cocaine and saline self-administration for 3-4 days (panel A, n = 7) or 21-22 days (panel B, $n=7$ ). Prior to drug challenges, animals were habituated to the locomotor cages for two hours. Horizontal activity is expressed as $\mathrm{cm} \pm$ S.E.M. traveled in 10-min intervals. Quinpirole produced a sensitized locomotor response in cocaine trained animals both after short-term $(F(1,168)=13.69, p=.0030)$ and long-term $(F(1,180)=$ $6.98, p=.02)$ withdrawal. 

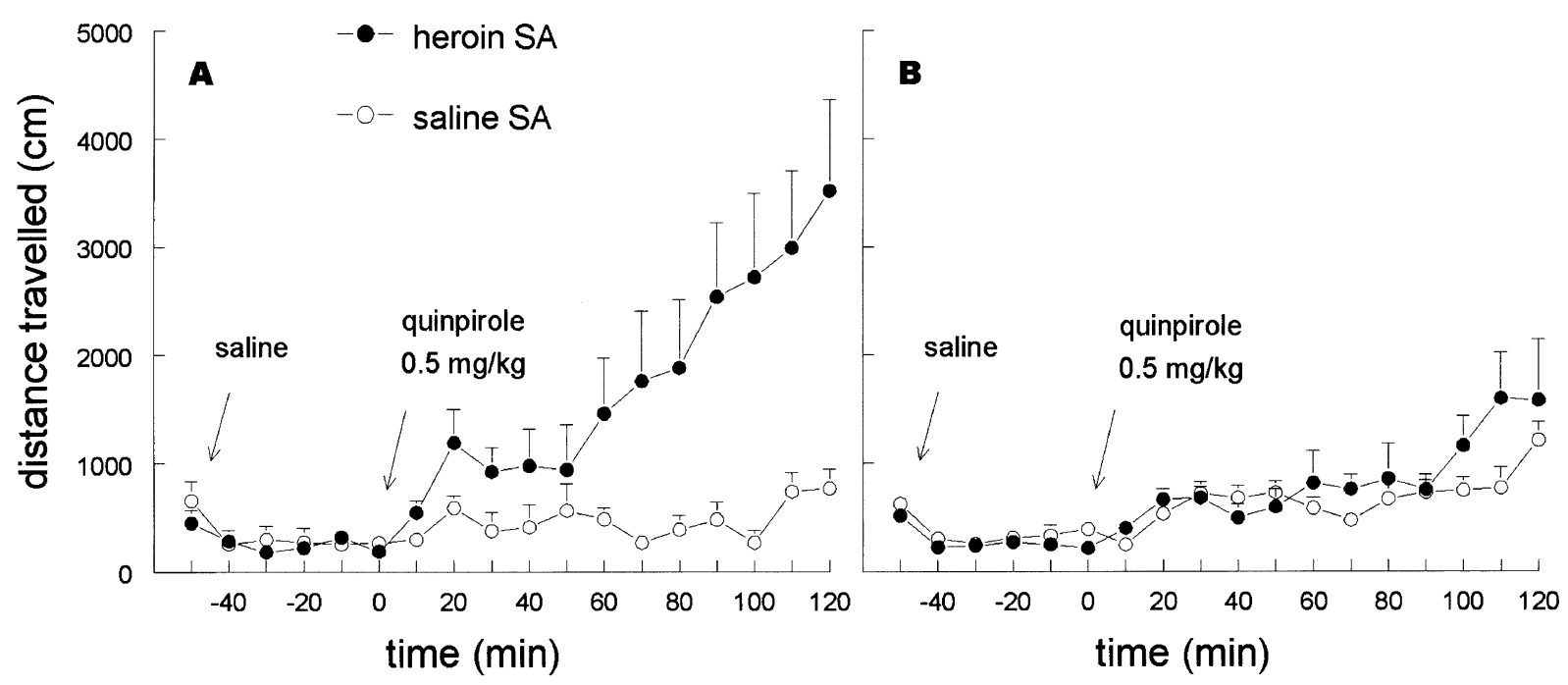

Figure 4. Locomotor effects of quinpirole following heroin self-administration. Locomotor activity analysis after saline and quinpirole $(0.5 \mathrm{mg} / \mathrm{kg}, \mathrm{SC})$ injection in animals withdrawn from heroin and saline self-administration for 3-4 days (panel A, $\mathrm{n}=8$ ) or 21-22 days (panel $\mathbf{B}, \mathrm{n}=8$ ). Prior to drug challenges, animals were habituated to the locomotor cages for two hours. Horizontal activity is expressed as $\mathrm{cm} \pm$ S.E.M. traveled in 10-min intervals. Quinpirole produced a sensitized locomotor response in heroin-trained animals after short-term $(\mathrm{F}(1,192)=9.73, p=.0089)$, but not long-term $(\mathrm{F}(1,187)=0.85$, NS) withdrawal.

clined over time, indicating that the role of $\mathrm{D} 2$ receptors in relapse behavior has a transient character. However, in cocaine-trained animals, quinpirole-induced drug seeking and behavioral sensitization was still observed after an withdrawal period of three weeks. The strong temporal relationship between drug hyperresponsiveness and drug seeking, suggests that the sensitizing effects of drugs of abuse play a permissive role in drug-induced relapse behavior.

The pharmacological actions of dopamine in the central nervous system are mediated by at least five receptor types (D1 through D5)(Lachowicz and Sibley 1997; Vallone et al. 2000). However, due to a lack of selective ligands and based on their physiological role, a subdivision in D1-like and D2-like responses is still customary. So far, studies with more or less selective dopamine ligands have suggested that activation of D2-like receptors mediates to incentive to seek cocaine, whereas activation of D1-like receptors by itself is ineffective and, in fact, may attenuate the priming effects of cocaine (Self et al. 1996; De Vries et al. 1999). Interestingly, the observation of opposing D1- and D2-like receptors mediating cocaine seeking was recently reproduced in nonhuman primates (Khroyan et al. 2000). The D2-like agonists used in these studies have considerable, or even higher, affinity for D3 receptors. However, recent observations indicate that selective activation of $\mathrm{D} 3$ receptors is not sufficient to reinstate cocaine seeking. Thus, studies with the D3 preferring agonist PD128,907 (Pugsley et al. 1995; De Boer et al. 1997), show that cocaine seeking could only be observed at doses that activate D2 recep- tors as well (unpublished data and see Khroyan et al. 2000).

Our results show that the priming effects of quinpirole on cocaine- and heroin-seeking clearly declined over time. In fact, quinpirole was unable to reinstate responding in heroin-trained animals following prolonged abstinence ( $>3$ weeks) and, at that time-point, its effect in cocaine-trained animals was substantially lower. In contrast, previous studies using an identical protocol show that at this stage of withdrawal $(>3$ weeks), priming with cocaine, amphetamine and heroin is still very effective in reinstating drug seeking (De Vries et al. 1998b, 1999). This indicates that activation of D2 receptors alone can not fully account for the longlasting effects of drug priming.

One might argue that the prolonged extinction training may have led to the reduction in the efficacy of quinpirole to reinstate drug seeking in the long-term withdrawal group. So far, the influence of extinction on reinstatement of drug seeking behavior has not been studied systematically. One should keep in mind, however, that in this paradigm the stimuli used to reinstate behavior, i.e. priming with quinpirole, were never experienced and/or extinguished. Since the animals were never exposed to the effects of the priming drug during training and extinction, it seems unlikely that the efficacy of this stimulus to trigger drug seeking would diminish with prolonged extinction training.

With respect to the neuronal substrates involved in mediating these incentive-motivational effects of drugs of abuse, studies by Stewart and co-workers have indi- 
cated that the priming effects of systemically given drugs are mimicked by the activation of the mesolimbic dopamine system. Thus, direct infusion of amphetamine into the nucleus accumbens or morphine into the ventral tegmental area (VTA), conditions that results in enhanced accumbens DA overflow, were found to reinstate heroin and cocaine seeking (Stewart 1984; Stewart and Vezina 1988).

It is well established now that repeated exposure to psychostimulants and opiates results in temporal changes in the releasability of mesolimbic dopamine (Wolf et al. 1993; Kalivas and Duffy 1993; Tjon et al. 1994; Paulson and Robinson 1995; Neisewander et al. 1996; Tran-Nguyen et al. 1998). Thus, releasability of dopamine is often diminished or unaffected during early drug withdrawal periods, i.e. within the first week (e.g. Rossetti et al. 1992) and facilitated during longer abstinence periods (for recent review: Vanderschuren and Kalivas 2000). These and other findings have questioned the involvement of dopamine in drug seeking behavior. Our present results, however, indicate that supersensitivity of D2 receptor-mediated events may counteract a diminished or unaffected releasability of dopamine during early drug withdrawal. The molecular and neurochemical basis of the enhanced D2 receptor mediated behavioral responsiveness remains to be clarified. Thusfar, studies examining changes at the level of the D2 receptor during or following cocaine and opiate treatment show that D2 receptor density and function in the accumbens does not seem to be altered (Henry and White 1991; King et al. 1994; Unterwald et al. 1994; Bonhomme et al. 1995; Nestby et al. 1997).

Although elevation of nucleus accumbens dopamine has been shown to trigger drug seeking (Stewart 1984; Stewart and Vezina 1988; Cornish and Kalivas 2000), the site of action of quinpirole-mediated drug seeking remains to be elucidated. The recent observation that the priming effects of cocaine on drug seeking were blocked by an intra-accumbens infusion of an AMPA antagonist, but not a dopamine antagonist (Cornish and Kalivas 2000), suggests that dopamine transmission outside the nucleus accumbens (in particular in regions sending glutamatergic projections to the accumbens) may play an important role as well. This seems in line with increasing evidence that dopaminergic projections to the amygdala modulate reinstatement of cocaineseeking behavior (Tran-Nguyen et al. 1998; Everitt et al. 1999).

The fact that facilitated release of dopamine develops with a certain delay, would also implicate that the impact of dopamine-releasing stimuli on drug seeking may increase over time. Indeed, Neisewander and coworkers observed that cocaine-induced drug seeking showed a significant increase between the first week and one month of withdrawal from cocaine self-admin- istration (Tran-Nguyen et al. 1998). In accordance with this line of reasoning are the observations that rats responding for cocaine-associated cues exhibited a diminished dopamine overflow in the nucleus accumbens one week after the last cocaine self-administration session (Neisewander et al. 1996), whereas Weiss and coworkers found that following a 3-week withdrawal period dopamine overflow in both nucleus accumbens and basolateral amygdala was enhanced during responding for a cocaine cue (Weiss et al. 2000).

Thus, drug seeking may persist through long-lasting changes in dopamine and glutamate transmission, while the contribution of D2 mediated-events may play an important role during early drug withdrawal.

The locomotor stimulating effects of quinpirole were dramatically increased in both heroin- and cocainetrained rats during the first week of abstinence, indicating that repeated self-administration of these drugs of abuse had resulted in robust sensitization of D2-mediated effects. These observations extend earlier studies employing forced opiate and psychostimulant exposure paradigms (Ujike et al. 1990; Vanderschuren et al. 1999; Druhan et al. 2000). In animals with a history of heroin self-administration, behavioral sensitization to quinpirole was no longer apparent three weeks after the last heroin session. Remarkably, at this stage, quinpirole was no longer able to reinstate heroin seeking. Therefore, our data give further support to the idea that hyperresponsiveness to a drug may represent a critical determinant for the expression of its incentive-motivational effects (De Vries et al. 1998b, 1999; Vanderschuren et al. 1999). Thus, a sensitized state may serve as a conditio sine qua non for reinstatement of drug seeking. Indeed, in the 3-week abstinent cocaine-trained rats, quinpirole's ability to reinstate cocaine responding was again associated with the expression of a sensitized behavioral response. The sensitized response to quinpirole in the cocaine late withdrawal group was still quite robust as compared to the short withdrawal group. In other words, the degree of sensitization appears not to predict the degree of reinstatement, suggesting that the biological substrates mediating drug seeking and drug sensitization are largely overlapping, but not identical. Currently, studies are in progress to evaluate whether pharmacological readjustment of the sensitization process would lead to attenuation of drug seeking. These studies will clarify whether there is a causal relationship between both phenomena. However, with respect to the underlying mechanisms, it is interesting to note that dopaminergic and glutamatergic processes play a dominant role not only in drug seeking, but also in the development and expression of drug-induced behavioral sensitization (Vanderschuren and Kalivas 2000).

Recently, enhanced sensitivity to a D2 agonist was also observed in rats withdrawn from chronic mor- 
phine, i.e. in rats showing overt somatic signs of opiate withdrawal (Druhan et al. 2000). The present and previous studies indicate that this is not a necessary condition for the development of D2 hyperresponsiveness. Rats subjected to our or similar heroin self-administration paradigms, i.e. single or multiple 3-hour sessions per day, do not show naloxone-precipitated or spontaneous somatic withdrawal signs. Although more sensitive indices of withdrawal may reveal some level of withdrawal in our rats, it is important to note that a state of physical withdrawal per se does not lead to enhanced drug seeking, i.e. to reinstatement of heroin seeking behavior (Shaham and Stewart 1995; Shaham et al. 1996). Rather, our studies indicate that a sensitized state increases the vulnerability to relapse to drug seeking.

Taken together, both the time-dependent changes in the sensitivity of neurobiological substrates that mediates relapse behavior as well as the proposed role of drug sensitization may have strong implications for the treatment of drug addiction. It emphasizes the need to develop tools that more specifically intervene with the different stages of the complicated process that results in relapse behavior in humans. Thus, readjustment of substrate hyperresponsiveness underlying drug sensitization during distinct phases of withdrawal may prove to be a more beneficial approach to the clinical management of addiction behavior. The fact that these factors have not been considered thus far in pharmacotherapies may explain the limited effectiveness of current treatment protocols in relapse prevention.

\section{ACKNOWLEDGMENTS}

The authors wish to thank Dr. L. van Wolfswinkel for providing additional software used for data analysis.

\section{REFERENCES}

Bonhomme N, Cador M, Stinus L, Le Moal M, Spampinato U (1995): Short and long-term changes in dopamine and serotonin receptor-binding sites in amphetamine-sensitized rats-a quantitative autoradiographic study. Brain Res 675:215-223

Cornish JL, Kalivas PW (2000): Glutamate transmission in the nucleus accumbens mediates relapse in cocaine addiction. J Neurosci 20:U11-U15

De Boer P, Enrico P, Wright J, Wise LD, Timmerman W, Moor E, Dijkstra D, Wikstrom HV, Westerink BHC (1997): Characterization of the effect of dopamine $D_{3}$ receptor stimulation on locomotion and striatal dopamine levels. Brain Res 758:83-91

De Vries TJ, Schoffelmeer ANM, Binnekade R, Mulder AH, Vanderschuren LJMJ (1998a): MK-801 reinstates drugseeking behaviour in cocaine-trained rats. Neuroreport 9:637-640

De Vries TJ, Schoffelmeer ANM, Binnekade R, Mulder AH,
Vanderschuren LJMJ (1998b): Drug-induced reinstatement of heroin- and cocaine-seeking behaviour following long-term extinction is associated with expression of behavioural sensitization. Eur J Neurosci 10:3565-3571

De Vries TJ, Schoffelmeer ANM, Binnekade R, Vanderschuren LJMJ (1999): Dopaminergic mechanisms mediating the incentive to seek cocaine and heroin following long-term withdrawal of IV drug self-administration. Psychopharmacol 143:254-260

De Wit H (1996): Priming effects with drugs and other reinforcers. Exp Clin Psychopharmacol 4:5-10

Deroche V, Le Moal M, Piazza PV (1999): Cocaine self-administration increases the incentive motivational properties of the drug in rats. Eur J Neurosci 11:2731-2736

Druhan JP, Walters CL, Aston-Jones G (2000): Behavioral activation induced by D2-like receptor stimulation during opiate withdrawal. J Pharmacol Exp Ther 294:531-538

Everitt BJ, Parkinson JA, Olmstead MC, Arroyo M, Robledo P, Robbins TW (1999): Associative processes in addiction and reward-The role of amygdala-ventral striatal subsystems. Ann NY Acad Sci 877:412-438

Henry DJ, White FJ (1991): Repeated cocaine administration causes persistent enhancement of D1 dopamine receptor sensitivity within the rat nucleus accumbens. J Pharmacol Exp Ther 258:882-890

Jaffe JH, Cascella NG, Kumor KM, Sherer MA (1989): Cocaineinduced cocaine craving. Psychopharmacol 97:59-64

Kalivas PW, Duffy P (1993): Time course of extracellular dopamine and behavioral sensitization to cocaine. I. Dopamine axon terminals. J Neurosci 13:266-275

Katner SN, Magalong JG, Weiss F (1999): Reinstatement of alcohol-seeking behavior by drug-associated discriminative stimuli after prolonged extinction in the rat. Neuropsychopharmacol 20:471-479

Khroyan TV, Barrett-Larimore RL, Rowlett JK, Spealman RD (2000): Dopamine D1-and D2-like receptor mechanisms in relapse to cocaine-seeking behavior: effects of selective antagonists and agonists. J Pharmacol Exp Ther 294:680-687

King GR, Ellinwood EH, Silvia C, Joyner CM, Xue Z, Caron MG, Lee TH (1994): Withdrawal from continuous or intermittent cocaine administration-Changes in D-2 receptor function. J Pharmacol Exp Ther 269:743-749

Koob GF (1992): Drugs of abuse: anatomy, pharmacology and function of reward pathways. Tr Pharmacol Sci 13: 177-184

Kosten TR, Rounsaville BJ, Kleber HD (1986): A 2.5-year follow-up of depressions, life crises, and treatment effects on abstinence among opioid addicts. Arch Gen Psych 43:733-739

Lachowicz JE, Sibley DR (1997): Molecular characteristics of mammalian dopamine receptors. Pharmacol Toxicol 81:105-113

Ludwig AM, Wikler A, Stark LH (1974): The first drink: psychobiological aspects of craving. Arch Gen Psych 30: 539-547

McFall ME, Mackay PW, Donovan DM (1992): Combatrelated posttraumatic-stress-disorder and severity of substance-abuse in Vietnam veterans. J Stud Alcohol 53:357-363 
McFarland K, Ettenberg A (1997): Reinstatement of drugseeking behavior produced by heroin-predictive environmental stimuli. Psychopharmacol 131:86-92

Meyer RE, Mirin SM (1979): The heroin stimulus: implications for a theory of addiction. New York, Plenum Medical Book Company

Neisewander JL, O'Dell LE, Tran-Nguyen LT, Castaneda E, Fuchs RA (1996): Dopamine overflow in the nucleus accumbens during extinction and reinstatement of cocaine self-administration behavior. Neuropsychopharmacol 15:506-514

Nestby P, Schotte A, Janssen PM, Tjon GKH, Vanderschuren LJMJ, De Vries TJ, Mulder AH, Leysen JE, Schoffelmeer ANM (1997): Striatal dopamine receptors in rats displaying long-term behavioural sensitization to morphine. Synapse 27:262-265

O'Doherty F, Davies BJ (1987): Life events and addiction: A critical review. Br J Addict 82:127-137

Paulson PE, Robinson TE (1995): Amphetamine-induced time-dependent sensitization of dopamine neurotransmission in the dorsal and ventral striatum-a microdialysis study in behaving rats. Synapse 19:56-65

Pugsley TA, Davis MD, Akunne HC, Mackenzie RG, Shih YH, Damsma G, Wikstrom H, Whetzel SZ, Georgic LM, Cooke LW, Demattos SB, Corbin AE, Glase SA, Wise LD, Dijkstra D, Heffner TG (1995): Neurochemical and functional characterization of the preferentially selective dopamine D3 agonist PD 128907. J Pharmacol Exp Ther 275:1355-1366

Robinson TE, Berridge KC (1993): The neural basis of drug craving: an incentive-sensitization theory of addiction. Brain Res Rev 18:247-291

Rossetti ZL, Hmaidan Y, Gessa GL (1992): Marked inhibition of mesolimbic dopamine release-a common feature of ethanol, morphine, cocaine and amphetamine abstinence in rats. Eur J Pharmacol. 221:227-234

Self DW, Barnhart WJ, Lehman DA, Nestler EJ (1996): Opposite modulation of cocaine-seeking behavior by D1- and D2-like dopamine receptor agonists. Science 271:15861589

Self DW, Nestler EJ (1998): Relapse to drug-seeking: neural and molecular mechanisms. Drug Alcohol Dependence 51:49-60

Shaham Y, Erb S, Stewart J (2000): Stress-induced relapse to heroin and cocaine seeking in rats: a review. Brain Res Rev 33:13-33

Shaham Y, Rajabi H, Stewart J (1996): Relapse to heroinseeking in rats under opioid maintenance: the effects of stress, heroin priming, and withdrawal. J Neurosci 16: 1957-1963

Shaham Y, Rodaros D, Stewart J (1994): Reinstatement of heroin-reinforced behavior following long-term extinction-implications for the treatment of relapse to drug taking. Behav Pharmacol 5:360-364

Shaham Y, Stewart J (1995): Stress reinstates heroin-seeking in drug free animals - an effect mimicking heroin, not withdrawal. Psychopharmacol 119:334-341
Stewart J (1984): Reinstatement of heroin and cocaine selfadministration behavior in the rat by intracerebral application of morphine in the ventral tegmental area. Pharmacol Biochem Behav 20:917-923

Stewart J, Vezina P (1988): A comparison of the effects of intra-accumbens injections of amphetamine and morphine on reinstatement of heroin intravenous selfadministration behavior. Brain Res 457:287-294

Tjon GHK, De Vries TJ, Ronken E, Hogenboom F, Wardeh G, Mulder AH, Schoffelmeer ANM (1994): Repeated and chronic morphine administration causes differential long-lasting changes in dopaminergic neurotransmission in rat striatum without changing its delta- and kappa-opioid receptor regulation. Eur J Pharmacol 252: 205-212

Tran-Nguyen LL, Fuchs RA, Coffey GP, Baker DA, O'Dell LE, Neisewander JL (1998): Time-dependent changes in cocaine-seeking behavior and extracellular dopamine levels in the amygdala during cocaine withdrawal. Neuropsychopharmacol 19:48-59

Ujike H, Akiyama K, Otsuki S (1990): D-2 but not D-1 dopamine agonists produce augmented behavioral-response in rats after subchronic treatment with methamphetamine or cocaine. Psychopharmacol 102:459-464

Unterwald EM, Ho A, Rubenfeld JM, Kreek MJ (1994): Timecourse of the development of behavioral sensitization and dopamine-receptor up-regulation during binge cocaine administration. J Pharmacol Exp Ther 270:13871396

Vallone D, Picetti R, Borrelli E (2000): Structure and function of dopamine receptors. Neurosci Biobehav Rev 24:125132

Vanderschuren LJMJ, Schoffelmeer ANM, Mulder AH, De Vries TJ (1999): Dopaminergic mechanisms mediating the long-term expression of locomotor sensitization following pre-exposure to morphine or amphetamine. Psychopharmacol 143:244-253

Vanderschuren LJMJ, Kalivas PW (2000): Alterations in dopaminergic and glutamatergic transmission in the induction and expression of behavioral sensitization: a critical review of preclinical studies. Psychopharmacol 151:99-120

Weiss F, Maldonado-Vlaar CS, Parsons LH, Kerr TM, Smith DL, Ben-Shahar O (2000): Control of cocaine-seeking behavior by drug-associated stimuli in rats: Effects on recovery of extinguished operant-responding and extracellular dopamine levels in amygdala and nucleus accumbens. Proc Natl Acad Sci USA 97:4321-4326

Wise RA, Bozarth MA (1987): A psychomotor stimulant theory of addiction. Psychol Rev 94:469-492

Wise RA, Murray A, Bozarth MA (1990): Bromocriptine selfadministration and bromocriptine- reinstatement of cocaine-trained and heroin-trained lever pressing in rats. Psychopharmacol 100:355-360

Wolf ME, White FJ, Nassar R, Brooderson RJ, Khansa MR (1993): Differential development of autoreceptor subsensitivity and enhanced dopamine release during amphetamine sensitization. J Pharmacol Exp Ther 264: 249-255 